\title{
Investigation of the immunoreactivities of NOS enzymes and the effect of sumatriptan in adolescent rats using an experimental model of migraine
}

\author{
Semra Hiz Kurul · Savas Demirpence $\cdot$ Müge Kiray · \\ Kazim Tugyan · Osman Yilmaz · Galip Kose
}

Received: 9 May 2008/ Accepted: 7 July 2008/Published online: 8 August 2008

(C) Springer-Verlag 2008

\begin{abstract}
The aim was to investigate the immunoreactivities for NOS enzymes in frontal cortex and meningeal vessels after chemical stimulation of the subarachnoid space of adolescent rats and the effect of sumatriptan pretreatment on the immunoreactivities of the NOS enzymes. Male adolescent Wistar rats were used. Rats in group 1 did not taken intracisternal injection. Rats in group 2 were taken intracisternal autologous blood injection, but no sumatriptan pre-treatment. Rats in group 3 were taken intracisternal autologous blood injection, but they were taken sumatriptan pre-treatment. Tissue samples were investigated for the presence of NOS immunoreactivity. The mean values of immunolabeling intensities for NOS enzymes in frontal cortex and meningeal vessels were significantly increased in group 2 compared to group 1 . The mean values of immunolabeling intensities for NOS enzymes in frontal cortex and meningeal vessels were significantly reduced in group 3 compared to group 2 . These results suggest that, chemical stimulation of the subarachnoid space increased
\end{abstract}

\footnotetext{
S. H. Kurul $(\bowtie) \cdot S$. Demirpence

Department of Pediatric Neurology,

Dokuz Eylül University, Izmir, Turkey

e-mail: semra.kurul@deu.edu.tr

M. Kiray · K. Tugyan

Department of Histology and Embryology,

Dokuz Eylül University, Izmir, Turkey

O. Yilmaz

Department of Laboratory Animal Sciences,

Dokuz Eylül University, Izmir, Turkey

G. Kose

Department of Pediatrics, Dokuz Eylül University,

Izmir, Turkey
}

the immunoreactivities of NOS enzymes in the brain of adolescent rats. The increased NOS immunoreactivities could be antagonized by pre-treatment with sumatriptan.

Keywords Headache Migraine Adolescence $\cdot$ Nitric oxide $\cdot$ Nitric oxide synthase $\cdot$ Sumatriptan

\section{Introduction}

Migraine is the most common primary headache syndrome during childhood and adolescence [1]. However, the pathophysiology of migraine is not fully understood. The proposed theory for classical migraine pathophysiology is the trigeminovascular theory. The propagation of the cortical-spreading depression to the pain-sensitive trigeminal sensory fibers is believed to induce the headache [2-4]. Stimulation of the trigeminal sensory neurons results in the release of a number of vasoactive substances such as calcitonin gene-related peptide (CGRP), vasoactive intestinal peptide (VIP) and substance P (SP), which induce vascular dilatation and neurogenic inflammation [5-7]. In recent years, many studies demonstrated the participation of nitric oxide (NO) in the pathogenesis of headache. NO is formed from the amino acid L-arginine by nitric oxide synthases (NOS), namely endothelial NOS (eNOS), neuronal NOS (nNOS) and inducible NOS (iNOS). eNOS and nNOS are constitutively expressed in endothelial cells and neurons, respectively, and their expression is the object of regulation at the transcriptional, translational and post-translational levels. The synthesis of iNOS is induced by endotoxin and by inflammatory cytokines in macrophages and many other cell types [8]. It has been reported that NO plays an active role in dural vasodilatation, contributing to the pathogenesis of migraine. NO causes migraine-like headache in both 
control volunteers and headache patients that fulfills the International Headache Society criteria for migraine in sufferers for several hours after NO infusion [9-12]. But it is scarce if NOS enzymes are activated after stimulation of the trigeminal sensory neurons.

The well-known $5-\mathrm{HT}_{1 \mathrm{~B} / 1 \mathrm{D}}$ serotonin receptor agonist sumatriptan is commonly prescribed for the treatment of acute migraine attack. The therapeutic action of sumatriptan is thought to be consistent with neuronal inhibition. It was shown that sumatriptan could inhibit neurogenic meningeal dural vasodilatation caused by electrical stimulation. This action was thought to be via the inhibition of the release of CGRP from trigeminal sensory fibers innervating the cranial blood vessels [1315]. However, it is unclear if sumatriptan has any effect on NOS enzymes.

The aim of this study was to investigate the immunoreactivity for NOS enzymes in meningeal vessels and frontal cerebral cortex after the chemical stimulation of the subarachnoid space of adolescent rats and the effect of sumatriptan on the immunoreactivity for the NOS enzymes.

\section{Materials and methods}

The study protocol was approved by the Ethical Committee of Dokuz Eylül University Medical School (permit no:113-2006).

\section{Animals}

Male adolescent Wistar rats (Dokuz University School of Medicine, Izmir, Turkey) weighing $90-120 \mathrm{~g}$ were used. Animals were housed in an appropriate cage on a 12-h light/12-h dark cycle with free access to standard laboratory food and tap water. The animals were allowed to habituate to the housing facilities for at least 1 week before the starting of experiments. They were divided into three groups of seven animals each:

Group 1 served as the sham rats which were anaesthetized and catheterized but were not administered intracisternal autologous blood injection.

Group 2 served as the control rats which were anaesthetized, catheterized and administered $0.1 \mathrm{~mL}$ intracisternal autologous blood injection, but were not given sumatriptan pretreatment. Instead of sumatriptan, they were given physiological saline of the same volume intraperitoneally.

Group 3 was the study group, which were anaesthetized, catheterized and treated with sumatriptan succinate ( $0.3 \mathrm{mg} \mathrm{kg}^{-1}$ body weight, intraperitoneally) $2 \mathrm{~h}$ before intracisternal autologous blood injection [16].

\section{Procedures}

Rats were anaesthetized with sodium pentobarbital (45 mg kg${ }^{-1}$ body weight, intraperitoneally). As previously reported, a midline skin incision was performed from the occipital protuberance to cervical area [17]. Skin and soft tissue overlying the skull were removed and a catheter was introduced into the cisterna magna. In groups 2 and 3, $0.1 \mathrm{~mL}$ autologous blood was injected into the cisterna magna over about $1 \mathrm{~min}$ through the catheter. The rats were kept in a horizontal prone position for $30 \mathrm{~min}$ in order to facilitate the settling of blood in the basal cisterns. Sham animals were treated identically but received no intracisternal injection or sumatriptan pretreatment. Rats were killed at $1 \mathrm{~h}$ after intracisternal blood instillation.

Tissue processing, histology and immunohistochemistry

At the end of the experiment, brain tissues of rats were removed. Tissue samples were fixed in $10 \%$ formalin in phosphate buffer, processed by routine histological methods and embedded in paraffin blocks. Sections were cut by a microtome (Leica RM2255), and eNOS and nNOS immunohistochemistry was performed using an anti-eNOS (GeneTex, Inc.), and anti-nNOS (StressGen Biotechnologies Corp., Canada) antibodies. Sections were deparaffinized in xylene, and rehydrated through a graded ethanol series. They were then treated with $2 \%$ trypsin at $37^{\circ} \mathrm{C}$ for $15 \mathrm{~min}$. Sections were incubated in a solution of $3 \% \mathrm{H}_{2} \mathrm{O}_{2}$ for $15 \mathrm{~min}$ to inhibit endogenous peroxidase activity. The sections were incubated overnight with anti-eNOS and anti-nNOS antibodies and then for another $30 \mathrm{~min}$ with the biotinylated mouse secondary antibody. The bound secondary antibody was then amplified with Vector Elite ABC kit ${ }^{\circledR}$ (Vectastain, Vector Laboratories, Burlingame, CA, USA). The antibody-biotin-avidin-peroxidase complexes were visualized using $0.02 \%$ DAB and nuclei were counterstained with Harris hematoxylin. The sections were finally mounted onto lysine-coated slides. The images were analyzed by using a computer-assisted image analyzer system consisting of a microscope (Olympus BX-50, Tokyo, Japan) equipped with a high-resolution video camera (JVC TK-890E, Japan). The immunolabeling scores were evaluated blindly. Immunolabeling intensity was graded as mild (1), moderate (2), strong (3) and very strong (4) [18].

Statistical analysis

All the statistical analyses were performed using computer program SPSS version 15 for windows (SPSS, Chicago, IL, 
USA). Results are presented as mean \pm SEM. All data were analyzed by one-way analysis of variance (ANOVA) post hoc Bonferroni test. $P<0.05$ was considered statistically significant.

\section{Results}

In animals which received $0.1 \mathrm{ml}$ of autologous blood into the cisterna magna, extensive clots were observed over the surface of the forebrain including the basal cisterns and the cisterns surrounding the basal cisterns. Immunohistochemical evaluation based on the intensities of eNOS and nNOS immunoreactivities in the brain tissue of frontal cortex is shown in Tables 1 and 2. Microphotographs of eNOS and nNOS immunoreactivities in frontal cortex are shown in Fig. 1. The mean values of the parenchymal eNOS immunolabeling intensities in the sham (group 1), control (group 2) and study (group 3) animals were $1.28 \pm 0.48,3.57 \pm 0.53$ and $2.57 \pm 0.53$, respectively

Table 1 The comparison of the immune staining in frontal cortex with eNOS antibodies between the sham, study and sumatriptan pretreatment groups

\begin{tabular}{|c|c|c|c|c|}
\hline Antibody & $\begin{array}{c}\text { Group } 1 \\
\text { (Sham group) } \\
(\mathrm{n}=7)\end{array}$ & $\begin{array}{c}\text { Group } 2 \\
\text { (Study group) } \\
(\mathrm{n}=7)\end{array}$ & $\begin{array}{c}\text { Group } 3 \\
\text { (Sumatriptan } \\
\text { pretreatment group) } \\
(\mathrm{n}=7)\end{array}$ & $\mathrm{p}$ \\
\hline eNOS & $1.28 \pm 0.48$ & $3.57 \pm 0.53$ & $2.57 \pm 0.53$ & 0.010 \\
\hline & & & & \\
\hline & & \multicolumn{2}{|c|}{$* * \mathrm{p}=0.006$} & \\
\hline
\end{tabular}

* Comparison between groups 1 and 2

** Comparison between groups 2 and 3

Table 2 The comparison of the immune staining in frontal cortex with nNOS antibodies between the sham, study and sumatriptan pretreatment groups

\begin{tabular}{|c|c|c|c|c|}
\hline Antibody & $\begin{array}{c}\text { Group } 1 \\
\text { (Sham group) } \\
(\mathrm{n}=7)\end{array}$ & $\begin{array}{c}\text { Group } 2 \\
\text { (Study group) } \\
(\mathrm{n}=7)\end{array}$ & $\begin{array}{c}\text { Group } 3 \\
\text { (Sumatriptan } \\
\text { pretreatment group) } \\
(n=7)\end{array}$ & $\mathrm{p}$ \\
\hline nNOS & $1.14 \pm 0.37$ & $3.28 \pm 0.75$ & $2.14 \pm 0.69$ & 0.019 \\
\hline & \multicolumn{2}{|c|}{$* \mathrm{p}=0.000$} & & \\
\hline & & \multicolumn{2}{|c|}{$* * \mathrm{p}=0.010$} & \\
\hline
\end{tabular}

* Comparison between groups 1 and 2

** Comparison between groups 2 and 3 


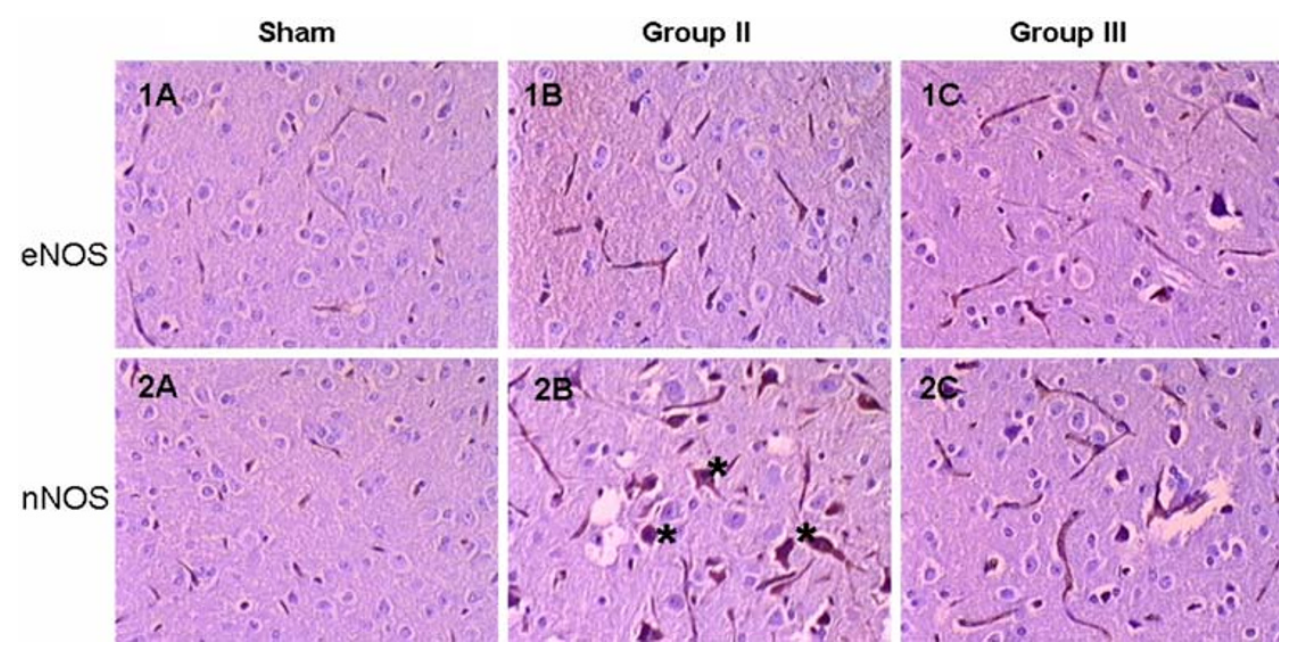

Fig. 1 Representative photomicrographs showing immunolabeling of eNOS and nNOS in the cerebral cortex of rats. a-c Show sections of sham, study (group II) and sumatriptan pretreatment groups (group III), respectively. Above photomicrographs of eNOS staining by immunohistochemistry. Below photomicrographs of nNOS staining by immunohistochemistry (as indicated by the asterisks). Significant positive immunolabeling was detectable in tissues from group II animals and a slight immunolabeling in group III $(\times 20)$
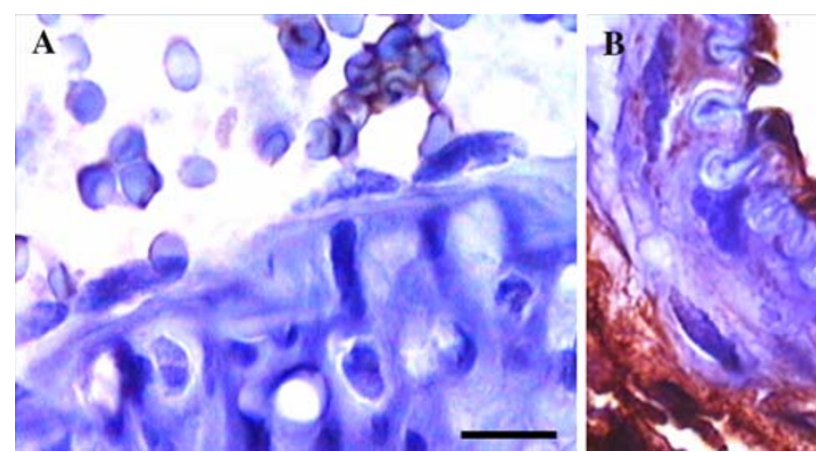

Fig. 2 Photomicrographs of eNOS staining by immunohistochemistry in the capillary endothelial cells. There was no eNOS immunoreactivity in sham group (a). The sections of group II

$(P=0.010)$. The mean values of the parenchymal nNOS immunolabeling intensities in the sham (group 1), control (group 2) and study (group 3) animals were $1.14 \pm 0.37$, $3.28 \pm 0.75,2.14 \pm 0.69$, respectively $(P=0.019)$.

According to the scoring system, the intensities of eNOS and nNOS immunolabeling in group 2 were found to have significantly increased compared to group $1(P=0.000$, $P=0.000$ respectively). The immunoreactivities for eNOS and nNOS in frontal cortex was significantly reduced in group 3 (animals treated with sumatriptan) when compared to group 2 ( $P=0.006, P=0.010$, respectively).

In meningeal vessels, numerous eNOS positive cells were seen after blood injection to the cisterna magna. Microphotographs of eNOS immunoreactivity in meningeal vessels are shown in Fig. 2. Immunohistochemical evaluation based on the intensities of eNOS immunoreactivity in meningeal vessels is demonstrated in Table 3. The mean values of the eNOS immunolabeling intensities in the
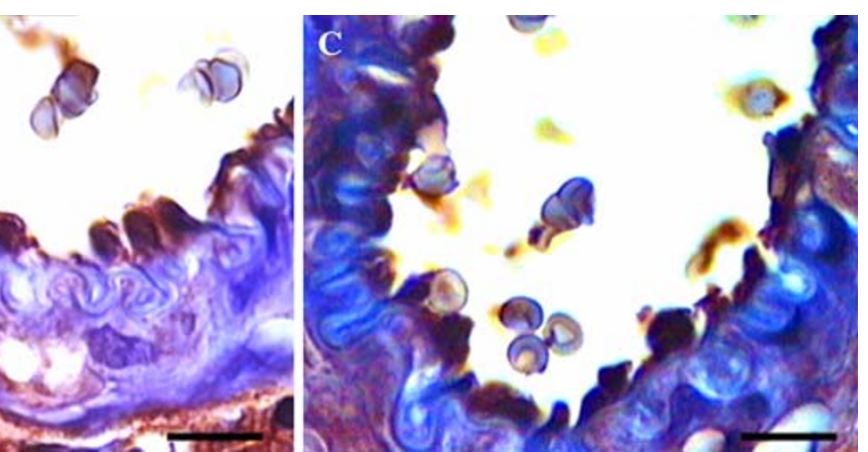

animals showed more intense labeling (b) and a slight eNOS immunoreactivity was observed in group III $(\mathbf{c})(\times 100)$

sham (group 1), control (group 2) and study (group 3) animals were $1.28 \pm 0.48, \quad 3.42 \pm 0.78,2.14 \pm 0.69$, respectively $(P=0.000)$. In group 2 , the immunoreactivity for eNOS was significantly increased when compared to group $1(P=0.000)$. The immunoreactivity for eNOS in meningeal vessels was significantly reduced in group 3 (animals treated with sumatriptan) when compared to group $2(P=0.006)$.

\section{Discussion}

Animal models have been extremely helpful to understand the migraine pathophysiology and in developing new therapeutic approaches [19]. It is noteworthy that almost all experimental studies in the field of primary headache research were performed in adult animals. On the other hand, primary headaches are not only the subject of the 
Table 3 The comparison of the immune staining in meningeal vessels with eNOS antibodies between the sham, study and sumatriptan pretreatment groups

\begin{tabular}{|c|c|c|c|c|}
\hline Antibody & $\begin{array}{l}\text { Group } 1 \\
\text { Sham group } \\
\qquad(\mathrm{n}=7)\end{array}$ & $\begin{array}{l}\text { Group } 2 \\
\text { Study group } \\
\qquad(\mathrm{n}=7)\end{array}$ & $\begin{array}{c}\text { Group } 3 \\
\text { (Sumatriptan } \\
\text { pretreatment group) } \\
\qquad(\mathrm{n}=7)\end{array}$ & $\mathrm{p}$ \\
\hline eNOS & $1.28 \pm 0.48$ & $3.42 \pm 0.78$ & $2.14 \pm 0.69$ & 0.000 \\
\hline & \multicolumn{2}{|c|}{$* \mathrm{p}=0.000$} & & \\
\hline & & \multicolumn{2}{|c|}{$* * \mathrm{p}=0.006$} & \\
\hline
\end{tabular}

* Comparison between groups 1 and 2

** Comparison between groups 2 and 3 adult people but also the adolescents and children also suffer from migraine, and it is well known that adult data did not always reflect the case of young people. In the literature, information is lacking about the pathophysiology of migraine headache in adolescent animals. We propose that our results might be helpful in understanding of the complex pathophysiology of migraine and in reflecting the data of the adolescents.

It has been demonstrated that chemical or electrical stimulation of the dura mater or of cranial blood vessels reproduces signs of migrainous pain. Electrical stimulation of the superior sagittal sinus in the cat leads to increased metabolic activity in the trigeminal nucleus caudalis and in the $\mathrm{C} 2$ region of the spinal cord [20]. Other studies also demonstrated a marked increase of the immediate early gene c-fos in laminae I and II of the trigeminal nucleus caudalis and the superficial layers of the $\mathrm{C} 1$ and $\mathrm{C} 2$ regions after stimulation of the middle meningeal artery, the superior sagittal sinus or the trigeminal ganglion in monkeys and cats [21-23]. Blood or blood products are the most likely stimulus of meningeal afferents, and in this regard, the instillation of homologous blood into the cisterna magna is used as an experimental model for migraine headache [19]. Earlier studies have investigated the pathophysiology of migraine in such a model of adult rats. It has been shown that blood in the subarachnoid space is an effective stimulus for activating the c-fos expression within subpopulations of brainstem neurons [17, 24]. We adapted this experimental model to adolescent rats. In the study presented here, autologous blood injected intracisternally was used for the stimulation of the trigeminovascular system. We thought that the significantly increased NOS immunoreactivities in meningeal vessels and frontal cortex of the animals demonstrate the efficient stimulus of autologous blood on the trigeminovascular system.

In recent years, immunohistochemical methods have begun to allow a better understanding the trigeminocervical interactions and inflammatory activation of the trigeminovascular system. The nerve cell bodies of the trigeminal ganglion express various neurotransmitters including CGRP, SP, PACAP and NO [25]. There is evidence that the turnover of the neuropeptides such as CGRP and SP increases after blood is injected into the subarachnoid space. However, the mechanisms by which trigeminal afferent axons become activated are not well understood [17]. NO has been proposed to be a key molecule in migraine. Experimental evidence suggests its intervention in vasodilatation and activation of the trigeminovascular system and its implication in coupling neuronal and vascular changes during spreading depression [9]. In our study, numerous NOS immunoreactive cells were observed in response to the injection of blood in meningeal vessels and brain parenchyma. These data support that NOS enzymes are activated after trigeminovascular stimulation.

In our study, we investigated the immunoreactivity of eNOS and nNOS enzymes in the brain parenchyma and meningeal vessels of the adolescent rats. iNOS is the inducible isoform of NOS enzymes. It has been reported that iNOS requires a delay of $6-8 \mathrm{~h}$ before the onset of NO production [26]. Because iNOS is not constitutively expressed in neurons or endothelial cells, we did not investigate the presence of iNOS immunoreactivity. Newer 
studies demonstrated the iNOS expression in central nervous system and in microglia cells $[27,28]$. We thought that, iNOS immunoreactivity might be investigated in the future studies of migraine using further experimental methods.

The mechanism of action of anti-migraine compounds is of interest in the context of developing new treatment strategies. Experimental studies demonstrated a marked increase of the immediate early gene c-fos in laminae I and II of the trigeminal nucleus caudalis and the superficial layers of the $\mathrm{C} 1$ and $\mathrm{C} 2$ regions after stimulation of the middle meningeal artery, the superior sagittal sinus or the trigeminal ganglion in monkeys and cats [21-23]. This response is reduced by anti-migraine agents, such triptans [29-31]. It has been shown that, both in vitro and in vivo, $5-\mathrm{HT}_{1 \mathrm{~B}}$ binding sites are present in very low concentration in trigeminal nucleus caudalis and cervical dorsal horn, below $12 \%$ of total specific sumatriptan binding. Similarly, $5-\mathrm{HT}_{1 \mathrm{D}}$ receptors also account for about $50 \%$ of the total specific binding [32]. These results gave weight to the proposal that antimigraine action of sumatriptan could in part be exerted via other mechanisms. It has been reported that sumatriptan inhibits the NO response by inhibiting trigeminal activation and CGRP release [33]. Similarly, it has been suggested that triptans prevent the release of CGRP from perivascular nerve terminals in the dura mater by an action at $5-\mathrm{HT}_{1 \mathrm{~B} / 1 \mathrm{D}}$ receptors [34]. Suwattanasophon et al. have shown that sumatriptan pretreatment attenuated the nitroglycerin-evoked expression of nNOS in trigeminal ganglia, trigeminal nucleus caudalis and perivascular nerve fiber surrounding superior sagittal sinus of the rats. They suggested that $5-\mathrm{HT}_{1 \mathrm{~B} / 1 \mathrm{D}}$ receptor has an important role in stabilizing the trigeminovascular system by attenuating the expression of nNOS enzyme and reducing nitric oxide production [35]. In our study, it was determined that sumatriptan administered $2 \mathrm{~h}$ before intracisternal autologous blood injection significantly reduced the intensity of increased eNOS immunolabeling both in brain parenchyma and meningeal vessels, and nNOS immunolabeling in brain parenchyma of the adolescent rats. It has been reported that the density of $5-\mathrm{HT}_{1 \mathrm{~B}}$ receptors are found to be increased in the frontal cortex in the rat brain [36]. With the aim to identify the effect of sumatriptan, the immunoreactivities of the NOS enzymes were investigated both in the frontal cortex and the meningeal vessels in our study. We speculated that sumatriptan had an inhibitory effect on the release of the NOS enzymes in adolescent rats. But the understanding of the mode of this action needs further investigation.

In conclusion, chemical stimulation of the meninges using autologous blood in adolescent rats increased the immunoreactivities of eNOS and nNOS enzymes in the frontal cortex and of eNOS enzyme in meningeal vessels, and thereby the formation of NO in brain parenchyma and meningeal vessels. Pretreatment with the antimigraine drug, sumatriptan, prevented the immunoreactivities of eNOS and nNOS enzymes in the meningeal vessels and the frontal cortex of the adolescent rats. These results indicate the participation of NOS enzymes in migraine pathophysiology and suggest that, in the future, specific NOS enzyme inhibitors could serve as pharmacological agents to treat migraine headache.

Conflict of interest None.

\section{References}

1. Lewis DW (2006) Headaches in infants and children. In: Swaiman KF, Ashwal S (eds) Pediatric neurology, 4th edn. Mosby Press, St Louis, pp 1183-1202

2. Dalkara T, Zervas NT, Moskowitz MA (2006) From spreading depression to the trigeminovascular system. Neurol Sci 27(Suppl 2):86-90

3. Pietrobon D, Striessnig J (2003) Neurobiology of migraine. Nat Rev 4:386-398

4. Goadsby PJ, Lipton RB, Ferrari MD (2002) Migraine-current understanding and treatment. N Engl J Med 346:257-270

5. Buzzi MG, Moskowitz MA (2005) The pathophysiology of migraine: year 2005. J Headache Pain 6:105-111

6. Uddman R, Tajti J, Hou M, Sundler F, Edvinsson L (2002) Neuropeptide expression in the human trigeminal nucleus caudalis and in the cervical spinal cord $\mathrm{C} 1$ and $\mathrm{C} 2$. Cephalalgia 22:112-116

7. Goadsby PJ, Edvinsson L, Ekman R (1990) Vasoactive peptide release in the extracerebral circulation of humans during migraine headache. Ann Neurol 28:183-187

8. Zinck T, Illum R, Jansen-Olesen I (2005) Increased expression of endothelial and neuronal nitric oxide synthase in dura and pia mater after air stres. Cephalalgia 26:14-25

9. Olesen J, Thomsen LL, Iversen HK (1994) Nitric oxide is a key molecule in migraine and other vascular headaches. Trends Pharmacol Sci 15:149-153

10. Iversen HK, Olesen J, Tfelt-Hansen P (1989) Intravenous nitroglycerin as an experimental headache model: basic characteristics. Pain 38:17-24

11. Strecker T, Dux M, Messlinger K (2002) Nitric oxide releases calcitonin-gene-related peptide from rat dura mater encephali promoting increases in meningeal blood flow. J Vasc Res 39:489496

12. Strecker T, Dux M, Messlinger K (2002) Increase in meningeal blood flow by nitric oxide-interaction with calcitonin gene-related peptide receptor and prostaglandin synthesis inhibition. Cephalalgia 22:233-241

13. Major PW, Grubisa HSI, Thie NMR (2003) Triptans for treatment of acute pediatric migraine: A systematic literature review. Pediatr Neurol 29:425-429

14. Akerman S, Williamson DJ, Kaube H, Goadsby PJ (2002) The effect of anti-migraine compounds on nitric oxide-induced dilation of dural meningeal vessels. Eur J Pharmacol 452:223228

15. Akerman S, Williamson DJ, Kaube H, Goadsby PJ (2002) Nitric oxide synthase inhibitors can antagonize neurogenic and calcitonin gene-related peptide induced dilation of dural meningeal vessels. Br J Pharmacol 137:62-68 
16. Bingham S, Davey PT, Sammons M, Raval P, Overend P, Parsons AA (2001) Inhibition of inflammation-induced thermal hypersensitivity by sumatriptan through activation of $5-\mathrm{HT}_{1 \mathrm{~B} / 1 \mathrm{D}}$ receptors. Exp Neurol 167:65-73

17. Nozaki K, Boccalini P, Moskowitz MA (1992) Expression of c-fos-like immunoreactivity in brainstem after meningeal irritation by blood in the subarachnoid space. Neurosci 49:669-680

18. Liang Y, Fang M, Li J, Yew DT (2006) Immunohistochemical localization of endothelial isoform (eNOS) in human cerebral arteries and the aorta. Int J Neurosci 116:1403-1417

19. Bergerot A, Holland PR, Akerman S et al (2006) Animal models of migraine: looking at the component parts of a complex disorder. Eur J Neurosci 24:1517-1534

20. Goadsby PJ, Zagami AS (1991) Stimulation of the superior sagittal sinus increases metabolic activity and blood flow in certain regions of the brainstem and upper cervical cord of the cat. Brain 114:100-111

21. Kaube H, Keay KA, Hoskin KL, Bandler R, Goadsby PJ (1993) Expression of c-fos-like immunoreactivity in the caudal medulla and upper cervical spinal cord following stimulation of the superior sagittal sinus in the cat. Brain Res 629:95-102

22. Goadsby PJ, Hoskin KL (1997) The distribution of trigeminovascular afferents in the nonhuman primate brain Macaca nemestrina: a c-fos immunocytochemical study. J Anat 190:367375

23. Hoskin KL, Zagami AS, Goadsby PJ (1999) Stimulation of the middle meningeal artery leads to Fos expression in the trigeminocervical nucleus: a comparative study of monkey and cat. J Anat 194:579-588

24. Nozaki K, Moskowitz MA, Boccalini P (1992) CP-93, 129, sumatriptan, dihydroergotamine block c-fos expression within the rat trigeminal nucleus caudalis caused by chemical stimulation of the meninges. Br J Pharmacol 106:409-415

25. Tajti J, Uddman R, Möller S, Sundler F, Edvinsson L (1999) Messenger molecules and receptor mRNA in the human trigeminal ganglion. J Auton Nerv Syst 76:176-183

26. Beck KF, Eberhardt W, Frank $S$ et al (1999) Inducible NO synthase: role in cellular signaling. J Exp Biol 202:645-653
27. Viggiano E, Ferrara D, Izzo G et al (2008) Cortical spreading depression induces the expression of iNOS, HIF- $1 \alpha$, and LDH-A. Neuroscience 153:182-188

28. Napolitano M, Zei D, Centonze D et al (2008) NF-kB/NOS crosstalk induced by mitochondrial complex II inhibition: Implications for Huntington's disease. Neurosci Lett 434:241-246

29. Shepheard SL, Williamson DJ, Williams J, Hill RG, Hargreaves RJ (1995) Comparison of the effects of sumatriptan and the NK1 antagonist CP-99, 994 on plasma extravasation in dura mater and c-fos mRNA expression in trigeminal nucleus caudalis of rats. Neuropharmacology 34:255-261

30. Goadsby PJ, Hoskin KL (1996) Inhibition of trigeminal neurons by intravenous administration of the serotonin $(5 \mathrm{HT})_{1 \mathrm{~B} / \mathrm{D}}$ receptor agonist zolmitriptan (311C90): are brain stem sites therapeutic target in migraine? Pain 67:355-359

31. Hoskin KL, Kaube H, Goadsby PJ (1996) Sumatriptan can inhibit trigeminal afferents by an exclusively neural mechanism. Brain 119:1419-1428

32. Longmore JD, Shaw D, Smith D, Hopkins R, McAllister G, Pickard JD et al (1997) Differential distribution of 5-HT1B and 5HT1B-immunoreactivity within the human trigeminocerebrovascular system: implications fort he discovery of new antimigraine drugs. Cephalalgia 17:833-842

33. Akerman S, Williamson DJ, Kaube H, Goadsby PJ (2002) The effect of anti-migraine compounds on nitric oxide-induced dilatation of dural meningeal vessels. Eur J Pharmacol 452:223-228

34. Knyihár-Csillik E, Tajti J, Chadaide Z, Csillik B, Vécsei L (2001) Functional immunohistochemistry of neuropeptides and nitric oxide synthase in the nerve fibers of the supratentorial dura mater in an experimental migraine model. Microsc Res Tech 53:193-211

35. Suwattanasophon $S$, Phansuwan-Pujito $P$, Srikiatkhachorn A (2003) $5-\mathrm{HT}_{1 \mathrm{~B} / 1 \mathrm{D}}$ serotonin receptor agonist attenuates nitroglycerin-evoked nitric oxide synthase expression in trigeminal pathway. Cephalalgia 23:825-832

36. Manrique C, François-Bellan AM, Segu L, Becquet D et al (1994) Impairment of serotoninergic transmission is followed by adaptive changes in $5 \mathrm{HT}_{1 \mathrm{~B}}$ binding sites in the rat suprachiasmatic nucleus. Brain Res 663:93-100 